\title{
Inter-regional hybrids of native and invasive Centaurea solstitialis display intermediate competitive ability
}

\author{
Daniel Montesinos and Ragan M. Callaway
}

D. Montesinos (http://orcid.org/0000-0003-2893-0878) (danimontesinos@gmail.com) and R. M. Callaway, The Univ. of Montana, Division of Biological Sciences and the Inst. on Ecosystems, Missoula, MT, USA. DM also at: Centro de Investigaciones sobre Desertificación - CIDE (CSIC,UV,GV), Carretera Moncada-Náquera, Moncada, Spain, and Centre for Functional Ecology, Dept of Life Sciences, Univ. of Coimbra, Calçada Martim de Freitas, Coimbra, Portugal.

Invasive species can rapidly adapt to conditions in nonnative ranges, including changes in size and competitive ability. However, little is known about the heritability of such changes, and on the importance of hypothetical reintroductions in the maintenance of locally adapted traits. To test for this, we experimentally produced a cohort of Centaurea solstitialis of ancestry from either the native range in Spain, the invasive range in California, or inter-regional hybrids from both ranges. We then set up one-to-one competition experiments with the grass Bromus hordeaceus. Centaurea solstitialis individuals grown from seed produced from two Californian parents had almost twice the competitive effect on $B$. hordeaceus than descendants of two Spanish parents, whereas interregional hybrids between Spain and California showed intermediate values. These results suggest that, at this stage of invasion, homogenizing gene flow resulting from hypothetical re-introductions from the native range could lower their competitive effects on the invaded plant communities.

Geographic isolation can lead to genetic divergence between native and non-native ranges of exotic species, which often results in increased competitive ability in the non-native ranges (Maron et al. 2004, Hierro et al. 2013, Colautti and Lau 2015). Despite recent focus on the rapid evolution of competitive ability by exotic invaders, little is known about its heritability. Centaurea solstitialis is an annual weed native to southern Europe, it is not involved in inter-specific hybridization events, and has been introduced into South and North America, where it presents a number of local adaptations and became an aggressive invader (Graebner et al. 2012, Montesinos et al. 2012, García et al. 2013, Eriksen et al. 2014). When the competitive ability of $C$. solstitialis plants from native Spanish and non-native Californian populations was compared to the competitive ability of intra-specific inter-regional hybrids from those regions (see Supplementary material Appendix 1 for methods), we did not find differences among seed ancestries for the competitive effect of $B$. hordeaceus on $C$. solstitialis
$\left(F_{3,33}=0.648 ; p=0.521\right)$. However, there were differences among seed ancestries in the competitive effects of C. solstitialis on $B$. hordeaceus $\left(\mathrm{F}_{3,35}=3.411 ; \mathrm{p}=0.016\right)$. Pure Spanish plants had the weakest competitive effect on $B$. hordeaceus, whereas descendants of Californian mothers had the strongest competitive effect regardless of the father's origin - over twice as much as that of pure Spanish $C$. solstitialis, $(\mathrm{z}=3.601 ; \mathrm{p}=0.002$ and $\mathrm{z}=2.574 ; \mathrm{p}=0.050)$. Seeds with Spanish mothers and Californian fathers presented intermediate values ( $p<0.200$; Fig. 1$)$, indicating an intermediate expression of the traits responsible for increased competitive ability (see full methodology and results in Supplementary material Appendix 1). Our results are in strike contrast with those found for invasive species with traces of inter-specific hybridization, which typically show increased hybrid vigor (Schierenbeck and Ellstrand 2008).

Increased size and competitive ability are frequently the result of adaptive responses of exotic species to new environments in their non-native ranges, although they can also be the result of founder effects (Thébaud and Simberloff 2001, Bossdorf et al. 2005). Repeated introductions from the native regions have been found to be important contributors to this process by generally, although not always, increasing invasive success on the non-native ranges (Keller and Taylor 2010, Verhoeven et al. 2011, Zenni et al. 2014, Schrieber and Lachmuth 2016). In fact, C. solstitialis seems to have experienced several reintroductions at the initial stages of invasion, which is believed to have been important for the successful invasion of California (Eriksen et al. 2014). Nevertheless, homogenizing gene flow can result in the loss of locally adapted traits (Nosil 2012). Thus, the relative importance of new propagule introductions could depend on the stage of invasion: being potentially important at the initial stages, in which the high evolutionary potential derived from higher genetic diversity could favor the development of increased invasive ability; but perhaps less important at later stages, when individuals already adapted to the nonnative regions could experience a decrease in fitness due to hybridization with non-adapted migrants (Nosil 2012). Our results suggest that, at this stage of invasion, homogenizing 


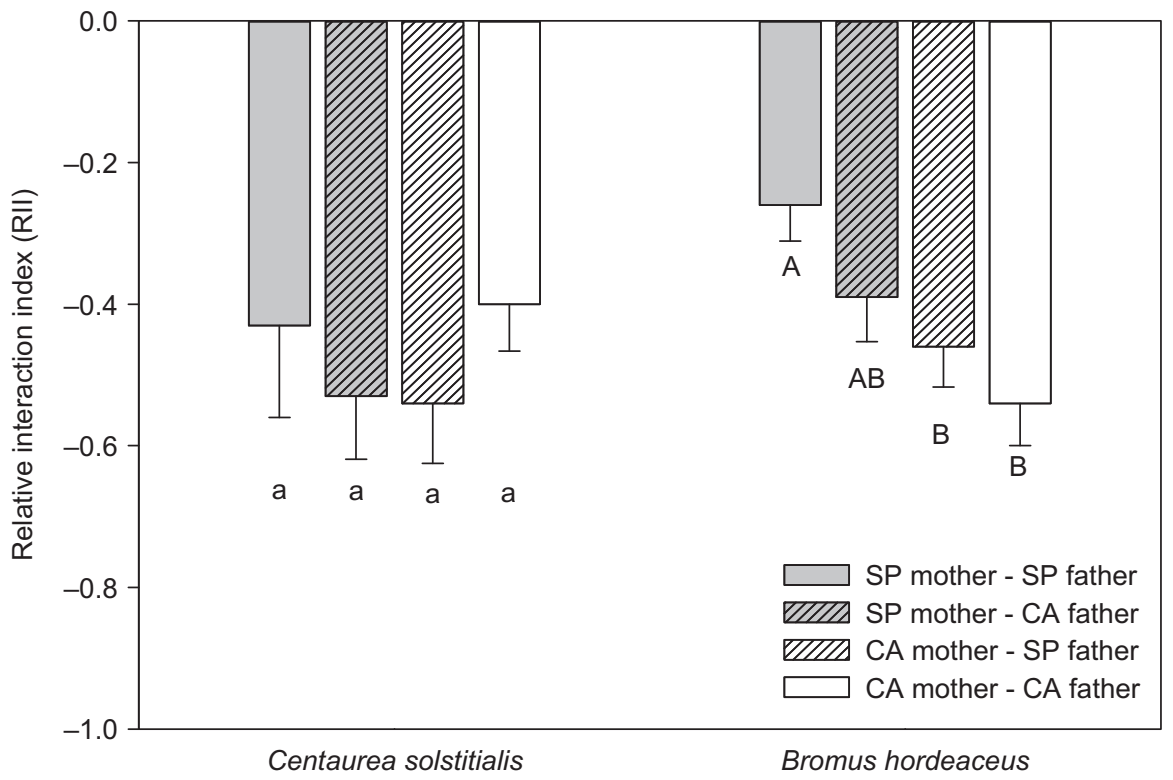

Figure 1. Relative interaction indexes (RII) indicate the relative strength of competition for pair-wise experiments between $C$. solstitialis intra- or inter-regional hybrids, and Bromus hordeaceus. More negative values indicate stronger competitive effects. CA denotes California, and SP denotes Spain. Grey columns represent Spanish mothers, and white columns represent Californian mothers. Columns with diagonal lines indicate inter-regional crosses (mean $\pm \mathrm{SE} ; \mathrm{N}_{\text {column }}=10$ ). Different lowercase or uppercase letters indicate statistically significantly differences among groups for either $C$. solstitialis or $B$. hordeaceus, respectively.

gene flow resulting from hypothetical new reintroductions from the native range might decrease the competitive effects of $C$. solstitialis on Californian plant communities. Regardless, the study of inter-regional hybrids proved to be an informative tool towards understanding the significance of trait-shifts between native and non-native regions of exotic species, and opens the door to future studies on the effects on gene flow to, and among, invading populations of different age. However, the assessment of trait expression both via backcrosses and further subsequent generations is highly advised to fully assess the extent of trait differentiation among crosses.

Data available from FigShare: <http://dx.doi.org/10.6084/ m9.figshare.3467936> (Montesinos and Callaway 2016).

Acknowledgements - Thanks to Margarita Zorrilla and to the Callaway Lab staff. RMC was funded by NSF-DEB 0614406 and the NSF-EPSCR Track-1 EPS-1101342 (INSTEP 3). DM was funded by Micinn (2008-0662); by FCT (PCT/BIAPLA/3389/2012; IF-00066-2013); and by the EC (FP7-PEOPLEMC-CIG-321909). FCT is partially funded by the EU via QREN, COMPETE and FEDER.

\section{References}

Bossdorf, O. et al. 2005. Phenotypic and genetic differentiation between native and introduced plant populations. - Oecologia 144: 1-11.

Colautti, R. I. and Lau, J. A. 2015. Contemporary evolution during invasion: evidence for differentiation, natural selection, and local adaptation. - Mol. Ecol. 24: 1999-2017.

Eriksen, R. L. et al. 2014. Dispersal pathways and genetic differentiation among worldwide populations of the invasive weed Centaurea solstitialis L. (Asteraceae). - PLoS One 9: e114786.
García, Y. et al. 2013. Invasive and non-invasive congeners show similar trait shifts between their same native and non-native ranges. - PLoS One 8: e82281.

Graebner, R. C. et al. 2012. Invasive species grows faster, competes better, and shows greater evolution toward increased seed size and growth than exotic non-invasive congeners. - Plant Ecol. 213: $545-553$.

Hierro, J. L. et al. 2013. Non-native conditions favor non-native populations of invasive plant: demographic consequences of seed size variation? - Oikos 122: 583-590.

Keller, S. R. and Taylor, D. R. 2010. Genomic admixture increases fitness during a biological invasion. - J. Evol. Biol. 23: $1720-1731$.

Maron, J. L. et al. 2004. Rapid evolution of an invasive plant. - Ecol. Monogr. 74: 261-280.

Montesinos, D. and Callaway, R. M. 2016. Data from: Interregional hybrids of native and invasive Centaurea solstitialis display intermediate competitive ability. - FigShare, <http:// dx.doi.org/10.6084/m9.figshare.3467936>

Montesinos, D. et al. 2012. Neo-allopatry and rapid reproductive isolation. - Am. Nat. 180: 529-533.

Nosil, P. 2012. Ecological speciation. - Oxford Univ. Press.

Schierenbeck, K. A. and Ellstrand, N. C. 2008. Hybridization and the evolution of invasiveness in plants and other organisms. - Biol. Invasions 11: 1093-1105.

Schrieber, K. and Lachmuth, S. 2016. The genetic paradox of invasions revisited: the potential role of inbreeding $X$ environment interactions in invasion success. - Biol. Rev. doi: 10.1111/ brv. 12263.

Thébaud, C. and Simberloff, D. 2001. Are plants really larger in their introduced ranges? - Am. Nat. 157: 231-236.

Verhoeven, K. J. F. et al. 2011. Population admixture, biological invasions and the balance between local adaptation and inbreeding depression. - Proc. R. Soc. B 278: 2-8.

Zenni, R. D. et al. 2014. Rapid evolution and range expansion of an invasive plant are driven by provenance-environment interactions. - Ecol. Lett. 17: 727-735.

Supplementary material (Appendix ECOG-02653 at < www. ecography.org/appendix/ecog-02653>). Appendix 1. 
Ecography

\section{Supplementary material}

ECOG-02653

Montesinos, D. and Callaway, R. M. 2016. Interregional hybrids of native and invasive Centaurea solstitialis display intermediate competitive ability. Ecography doi: 10.1111/ecog.02653 


\section{Appendix 1}

\section{Material and methods}

Centaurea solstitialis is an annual herb with a self-incompatible reproductive system (Sun and Ritland 1998), which greatly facilitates the experimental production of seeds of known ancestry via manual crosses. The species was introduced into California at the latest in 1824 (Maddox et al, 1985) where it has become an aggressive invader. Genetic data suggests that reintroductions into California have been frequent in the past (Dlugosch et al. 2013, Eriksen et al. 2014), but the absence of information about new introductions suggests that new reintroductions are unlikely (DiTomaso et al. 2006). Inter-specific hybridization is believed to provide with adaptive advantages to invasive species in the form of (1) evolutionary novelty; (2) increased genetic variation; (3) fixed heterosis; and (4) dumping genetic load, which typically result in enhanced vigor and invasive ability (Ellstrand and Schierenbeck 2000, Schierenbeck and Ellstrand 2008). However genetic studies found no traces of inter-specific hybridization on C. solstitialis (Garcia-Jacas et al. 2006, Dlugosch et al. 2013, Eriksen et al. 2014).

During the summer of 2009 we collected seeds from fifteen different individuals from ten different populations each across Spain and California (see Montesinos et al. 2012). Although the sampling was reasonably good, biogeographic studies of this kind can never completely discard that the detected differences between regions are not the result of founder effects (Bossdorf et al. 2005). Also, we can not differentiate if the detected patters would be the result of adaptive or non-adaptive evolutionary changes (Keller and Taylor 2008, Lachmuth et al. 2011) although this would not affect our conclusions. Two factors suggest that founder 
effects are unlikely to be important for our study: firstly, several biogeographic studies show a very similar pattern of increased competitive ability in Californian populations of $C$. solstitialis (Widmer et al. 2007, Graebner et al. 2012, García et al. 2013); secondly, regardless of potential bottleneck effects, the experimental design would still illustrate how increased competitive ability is inherited when populations of the same invasive species with significantly different levels of competitive ability are experimentally crossed.

In 2010, seeds from each individual were grown in common conditions in a greenhouse from which pollinators were excluded. Seeds were germinated and grown in pots, and each individual adult plant was subjected to a set of different manual pollination treatments. These included random cross-pollinations with other individuals from a different population within the same region, and with individuals from a different region (see detailed methodology in Montesinos et al. 2012). This produced four groups of seeds based on the geographic origin of their parents: seeds with a Californian mother and father; a Californian mother and a Spanish father; a Spanish mother and a Californian father; or a Spanish mother and father.

In 2011 we used these four kind of seeds (hereafter "treatments") to set up a common garden competition experiment in which seeds from each of the four treatments were grown either alone in control pots, or in competition with one individual Bromus hordeaceus. This European native annual grass has replaced Californian native grasses over large areas and thus has overlapping distributions with $C$. solstitialis both in their native range of Spain and in their invasive range of California (Hastings and Ditomaso 1996). Field-collected Bromus hordeaceus seeds from California were purchased from S\&S Seeds, Carpinteria, CA, USA. We used C. solstitialis F1 sibling individuals from the same specific father and mother for each replication between paired treatments (i.e. control and competition pots). 
The number competitor species to be used in our experiment was constrained by the limited number of inter-regional hybrid seed available, which made the choice of one single and well-known strong competitor species a need. Based on previous competition studies (Graebner et al. 2012) we chose B. hordeaceus as a strong competitor sharing the same European native range and American non-native range that $C$. solstitialis. Other studied native grasses were weak competitors and did not trigger sufficient competitive responses in $C$. solstitialis, and thus were deemed unsuitable for tests of biogeographical differences in competitive ability of $C$. solstitialis. Additionally, it would have been desirable to compare competition ability from $B$. hordeaceus seed from both native and non-native ranges; however, the complexity of such an experimental design and the limited availability of inter-regional hybrid seed made it unfeasible.

Sibling $C$. solstitialis seeds were planted either in control pots or in competition with $B$. hordeaceus in $200 \mathrm{~mL}$ Ray Leach Inc. Cone-Trainers pots in a 50:50 mix of 20-30 grit sand and soil from Missoula, MT, and watered every 1-2 days. Each treatment had ten control and ten competition replicates, with inter-regional hybrids being the result of crosses between random pairs of individuals from different pairs of native and non-native populations. A control group of $B$. hordeaceus was also sown ( $\mathrm{N}=30$ ). We fertilized each pot with $100 \mathrm{~mL}$ of $1.16 \mathrm{~g} \mathrm{~L}^{-1}$ Scotts Miracle-Gro (15 N:30 K:15 P + micronutrients) once, four weeks after germination. Plants were grown for 57 days, at which time their rosettes had reached roughly maximum sizes but growth of flowering stems had not started. Total shoot and root biomass was harvested and dried at $70^{\circ} \mathrm{C}$ for $48 \mathrm{~h}$ and then weighed. There was no mortality in the experiment. 
We used data for total dry biomass of $C$. solstitialis plants from each seed ancestry growing either in control pots or in competition with $B$. hordeaceus to calculate Relative Interaction Indices (Armas et al., 2004):

$$
R I I=\left(B_{w}-B_{0}\right) /\left(B_{w}+B_{0}\right),
$$

in which $\mathrm{B}_{0}$ corresponds to the biomass of a control individual, and $\mathrm{B}_{\mathrm{w}}$ corresponds to the biomass of a full sibling individual grown in competition. RII has defined limits $(-1,+1)$, with more negative values indicating stronger competition, and positive values indicating the strength of mutualistic interactions. We used RII's to test for differences among seed ancestries for each species via General Linear Models in R 3.1.2 (R Development Core Team 2010), with RII as the variable and each of the four possible combinations of $C$. solstitialis seed ancestry (pollen donor and pollen receiver) as the fixed treatment factor. Separate tests were used for $C$. solstitialis or B. hordeaceus biomass derived data. Tukey post-hoc tests were run when required by using the glht procedure in R's multcomp library.

\section{References}

Armas, C. et al. 2004. Measuring plant interactions: a new comparative index. - Ecology 85: 2682-2686.

Bossdorf, O. et al. 2005. Phenotypic and genetic differentiation between native and introduced plant populations. - Oecologia 144: 1-11. 
DiTomaso, J. M. et al. 2006. Yellow Starthistle Management Guide. Cal-IPC Publication 2006-03.

Dlugosch, K. M. et al. 2013. Allele Identification for Transcriptome-Based Population Genomics in the Invasive Plant Centaurea solstitialis. - G3 Genes | Genomes | Genet. 3: 359-67.

Ellstrand, N. C. and Schierenbeck, K. a 2000. Hybridization as a stimulus for the evolution of invasiveness in plants? - Proc. Natl. Acad. Sci. U. S. A. 97: 7043-50.

Eriksen, R. L. et al. 2014. Dispersal pathways and genetic differentiation among worldwide populations of the invasive weed Centaurea solstitialis L. (Asteraceae). - PLOS ONE 9: e114786.

García, Y. et al. 2013. Invasive and non-invasive congeners show similar trait shifts between their same native and non-native ranges. - PLOS ONE 8: e82281.

Garcia-Jacas, N. et al. 2006. Centaurea revisited: a molecular survey of the Jacea group. - Ann. Bot. 98: 741-53.

Graebner, R. C. et al. 2012. Invasive species grows faster, competes better, and shows greater evolution toward increased seed size and growth than exotic non-invasive congeners. - Plant Ecol. 213: 545553.

Hastings, M. and Ditomaso, J. 1996. The use of fire for yellow starthistle (Centaurea solstitialis) management and restoration of native grasslands at Sugarloaf Ridge State Park. - CaIEPPC News 4: $4-6$.

Keller, S. R. and Taylor, D. R. 2008. History, chance and adaptation during biological invasion: Separating stochastic phenotypic evolution from response to selection. - Ecol. Lett. 11: 852-866.

Lachmuth, S. et al. 2011. Differentiation of reproductive and competitive ability in the invaded range of Senecio inaequidens: the role of genetic Allee effects, adaptive and nonadaptive evolution. - New 
Phytol. 192: 529-41.

Maddox, D. M. et al. 1985. Distribution of yellow starthistle (Centaurea solstitialis) and russian knapweed (Centaurea repens). - Weed Sci. 33: 315-327.

Montesinos, D. et al. 2012. Neo-allopatry and rapid reproductive isolation. - Am. Nat. 180: 529-33.

R Development Core Team 2010. R: A Language and Environment for Statistical Computing (Austria, Ed.). - R Found. Stat. Comput. Vienna Austria 0: \{ISBN\} 3-900051-07-0.

Schierenbeck, K. a. and Ellstrand, N. C. 2008. Hybridization and the evolution of invasiveness in plants and other organisms. - Biol. Invasions 11: 1093-1105.

Sun, M. and Ritland, K. 1998. Mating system of yellow starthistle (Centaurea solstitialis), a successful colonizer in North America. - Heredity (Edinb). 80: 225-232.

Widmer, T. L. et al. 2007. Enhanced growth and seed properties in introduced vs. native populations of yellow starthistle (Centaurea solstitialis). - Weed Sci. 55: 465-473. 